\title{
TITLE:
}

\section{Improvement of Thermal Efficiency in a Diesel Engine with High- Pressure Split Main Injection}

\section{$\operatorname{AUTHOR}(S)$ :}

Horibe, Naoto; Bao, Zhichao; Taguchi, Tomoki; Egoshi, Kenta; Kawanabe, Hiroshi; Ishiyama, Takuji

\section{CITATION:}

Horibe, Naoto ...[et al]. Improvement of Thermal Efficiency in a Diesel Engine with HighPressure Split Main Injection. SAE Technical Papers 2018: 2018-01-1791.

\section{ISSUE DATE:}

2018-09-10

URL:

http://hdl.handle.net/2433/237661

\section{RIGHT:}

This is the accepted manuscript of the article, which has been published in final form at https://doi.org/10.4271/2018 01-1791:; The full-text file will be made open to the public on 10 March 2019 in accordance with publisher's 'Terms and Conditions for Self-Archiving'; This is not the published version. Please cite only the published version.; この論文は出版 社版でありません。引用の際には出版社版をご磪認じ利用ください。 


\title{
Improvement of Thermal Efficiency in a Diesel Engine with High-pressure Split Main Injection
}

\author{
Author, co-author (Do NOT enter this information. It will be pulled from participant tab in \\ MyTechZone) \\ Affiliation (Do NOT enter this information. It will be pulled from participant tab in MyTechZone)
}

\begin{abstract}
This study aims to utilize high-pressure split-main injection for improving the thermal efficiency of diesel engines. A series of experiments was conducted using a single-cylinder diesel engine under conditions of an engine speed of 2,250 rpm and a gross indicated mean effective pressure of 1.43 MPa. The injection pressure was varied in the range of 160-270 MPa. Split-main injection was applied to reduce cooling loss under the condition of high injection pressure, and the split ratio and the number of injection stages were varied. The dwell of the split main injection was set to near-zero in order to minimize the elongation of the total injection duration. As a result, thermal efficiency was improved owing to the combined increase in injection pressure, advanced injection timing, and split-main injection. According to the analysis of heat balance, a larger amount of the second part of the main injection decreased the cooling loss and increased the exhaust loss. Computational fluid dynamics calculations were performed to reveal the causes of the lower cooling loss; however, the results could not capture the experimental trend when using an ordinary spray cone angle. While using a wider spray angle for the second part of main injection, the calculated trend improved. The total cooling loss depends on the balance between the cooling losses by the first and second main sprays.
\end{abstract}

\section{Introduction}

Recent automotive diesel engines are designed to reduce exhaust emissions and improve thermal efficiency using high-pressure fuel injection, multiple injection, exhaust gas recirculation, supercharging, and after-treatment devices. Considering the great demand for $\mathrm{CO}_{2}$ reduction, further improvement of thermal efficiency is an urgent problem. Therefore, $50 \%$ or higher brake thermal efficiencies are set as targets in several projects [1-4].

In order to extensively improve thermal efficiency, a higher degree of constant volume (DCV) and a lower cooling loss should be realized simultaneously. For increasing the DCV, shortening the injection duration and increasing the fuel/air mixing rate by increasing the fuel injection pressure in addition to the optimization of the injection timing is an effective approach. However, the increase in DCV usually causes a negative effect on cooling loss. To reduce the cooling loss, an effective approach is to combine a large bore combustion chamber and a small nozzle-hole injector with an increased number of nozzle holes. For reducing the cooling loss by

Page 1 of 12 controlling combustion, Osada et al. [5] improved the thermal efficiency by using closed post injection. The amount of post injection was set approximately at $20 \%$ of the main injection amount, and the timing of the post injection was advanced as far as possible. In addition, we also reported that thermal efficiency slightly improved by advanced post injection [6]. In these studies, splitting the main injection, which means the so-called close post injection here, provides reduced cooling loss through the mitigation of main spray-flames' impingement on the combustion chamber walls. According to this assumption, a larger amount of post injection is preferred for further reducing cooling loss.

However, split injection tends to decrease the DCV because the entire injection and combustion durations become longer. Therefore, the increase in the injection duration should be minimized to fully utilize the advantage of split injection. From this viewpoint, in this study, we aimed at increasing thermal efficiency by splitting a main injection with a near-zero dwell. The effect of injection pressure and the split ratio on thermal efficiency were investigated using a single-cylinder diesel engine with a small bore $(85 \mathrm{~mm})$. Furthermore, the factor influencing the thermal efficiency was discussed based on the results of heat-balance analysis and computational fluid dynamics (CFD) simulation.

\section{Experimental Setup}

\section{Research engine system}

Figure 1 shows a schematic of the experimental engine system. The engine is a single-cylinder four-stroke diesel engine. Table 1 summarizes the major specifications of the engine. Figure 2 illustrates the shape of the combustion chamber. 


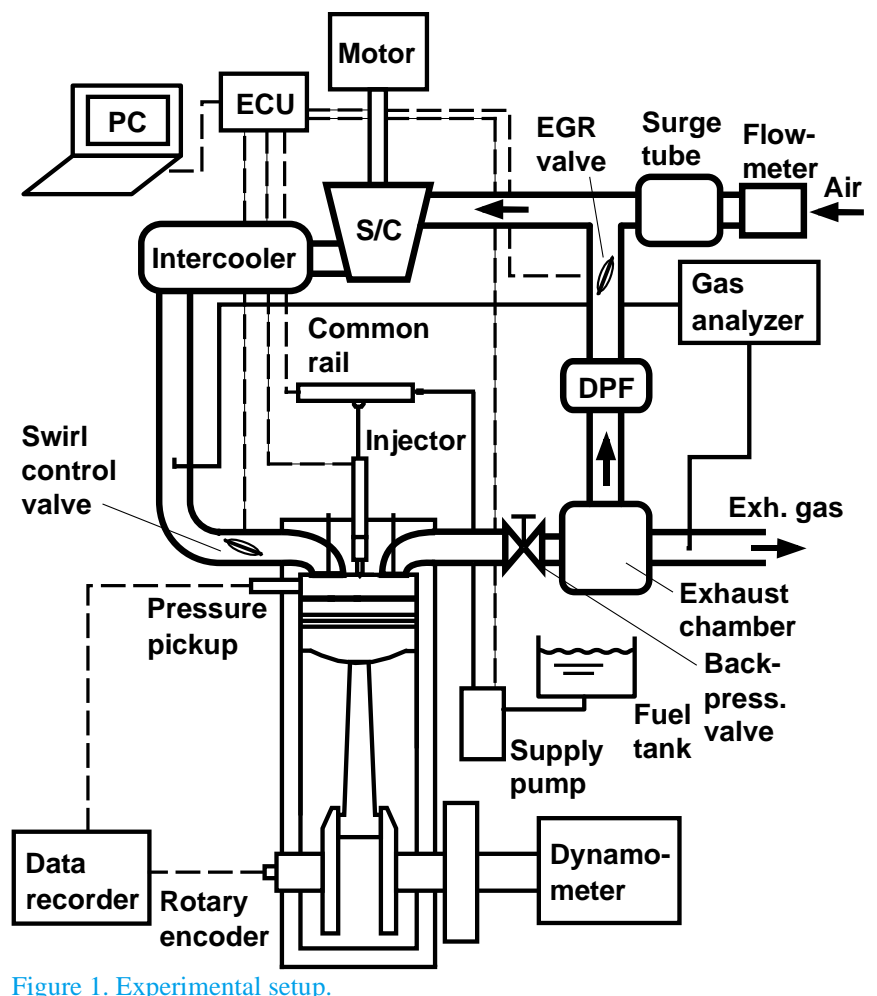

Table 1. Engine specification.

\begin{tabular}{|l|c|}
\hline Engine type & $\begin{array}{c}\text { Direct-injection diesel engine, } \\
\text { Single-cylinder, Water-cooled }\end{array}$ \\
\hline Bore $\times$ Stroke $[\mathrm{mm}]$ & $85.0 \times 96.9$ \\
\hline Displacement $\left[\mathrm{cm}^{3}\right]$ & 550 \\
\hline Compression ratio & 16.3 \\
\hline Injection system & $\begin{array}{c}\text { Common-rail system } \\
\phi 0.091 \mathrm{~mm} \times 10 \text { holes nozzle } \\
\left(156^{\circ} \text { included angle }\right)\end{array}$ \\
\hline Supercharging & External supercharging \\
\hline EGR system & Low-pressure loop \\
\hline
\end{tabular}

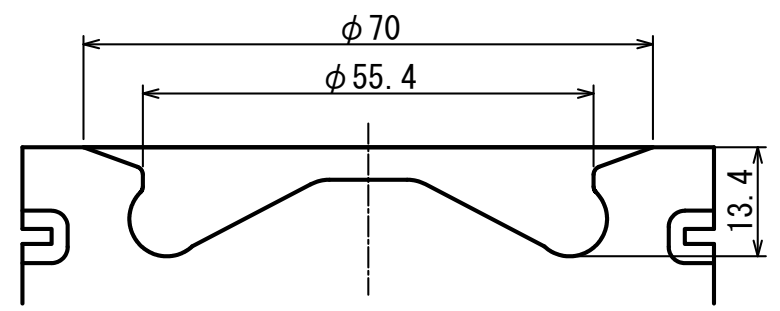

Figure 2. Combustion chamber shape.

This study aims to increase the thermal efficiency at an engine operating condition that provides the best thermal efficiency for a range of load and speed under a standard condition. Therefore, the speed and gross indicated mean effective pressure (IMEP) were set at 2,250 rpm and 1.43 MPa, respectively, in all the experiments. The standard injection pattern is pilot, pre, and main injection, as shown in Figure 3. The injection conditions are listed in Table 2. In the cases p160, p200, and p270, the injection pressures were elevated from 160

Page 2 of 12
$\mathrm{MPa}$, to $200 \mathrm{MPa}$ and to $270 \mathrm{MPa}$, respectively. The injection timings of p270A were advanced from those of p270. Split-main injection was applied to p270A and the split ratio was changed in the cases A1, A3, A5, and A8. Furthermore, in the case DA, the second part of the main injection in A8 was split into two parts. The schematic of the injection pattern of the case DA is shown in Figure 4.

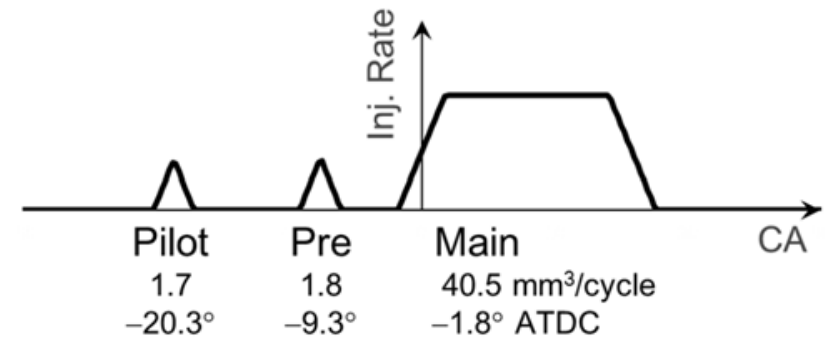

Figure 3. Standard injection condition (p160).

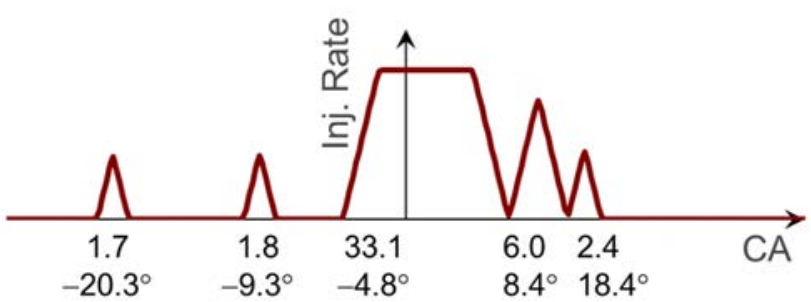

Figure 4. Injection condition of DA.

The NOx emissions in all cases were maintained at the conventional level ( $800 \mathrm{ppm}$ ) by adjusting the EGR rate, as shown in Table 2, in order to prevent the deterioration of NOx emission owing to the high injection pressure or the split injection.

The fuel was commercial JIS No. 2 diesel fuel (cetane index: 54).The fuel density at $15^{\circ} \mathrm{C}$ is $844.2 \mathrm{~kg} / \mathrm{m}^{3}$ and the lower heating value is $42.9 \mathrm{MJ} / \mathrm{kg}$, which were measured experimentally according to [7] and [8], respectively. The fuel temperature at the inlet of the fuel pump was set at $30^{\circ} \mathrm{C}$. The temperatures of coolant and lubricating oil were fixed at $80^{\circ} \mathrm{C}$. The intake and exhaust pressures were fixed at $180 \mathrm{kPa}$. The engine has a swirl control valve and the swirl ratio can be changed in the range of 1.3-3.2. Because a low swirl ratio is beneficial for improving the thermal efficiency, the ratio was set at 1.3 .

An engine exhaust gas analyzer (Horiba MEXA 1700DEGR) was used to measure the $\mathrm{NOx}, \mathrm{THC}, \mathrm{CO}, \mathrm{CO}_{2}$, and $\mathrm{O}_{2}$ concentrations, and the smoke emissions were acquired using a filter-type smoke meter (AVL 415S). The heat release rates were calculated from the incylinder pressure histories (50-cycle average) recorded by a pressure sensor (Kistler 6052C).

\section{Injection rate}

The injection rate was measured separately from the engine experiments by using a Bosch long-tube injection rate meter [9], and the fuel flow rate was measured simultaneously. The injection rates were calculated from 50 cycles of injection. A sensor output of injection rate meter of p160 is indicated in Figure 5. A waveform of injection rate shows a skirt at the end of injection. This seems to be 
Table 2. Injection conditions and EGR rates in experiments.

\begin{tabular}{|c|c|c|c|c|c|c|c|c|c|c|c|}
\hline \multicolumn{3}{|c|}{ Case } & $\mathrm{p} 160$ & $\mathrm{p} 200$ & $\mathrm{p} 270$ & $\mathrm{p} 270 \mathrm{~A}$ & $\mathrm{~A} 1$ & $\mathrm{~A} 3$ & A5 & A8 & DA \\
\hline \multicolumn{3}{|c|}{ Injection pattern } & N & & & A & N & & & 1 & \\
\hline \multicolumn{2}{|c|}{ Inj. pressure } & [MPa] & 160 & 200 & 270 & $\leftarrow$ & $\leftarrow$ & $\leftarrow$ & $\leftarrow$ & $\leftarrow$ & $\leftarrow$ \\
\hline \multirow[t]{2}{*}{ Pilot } & quantity & [mm³/cycle] & 1.7 & $\leftarrow$ & $\leftarrow$ & $\leftarrow$ & $\leftarrow$ & $\leftarrow$ & $\leftarrow$ & $\leftarrow$ & $\leftarrow$ \\
\hline & timing & {$\left[{ }^{\circ} \mathrm{ATDC}\right]$} & -20.3 & $\leftarrow$ & $\leftarrow$ & -23.3 & $\leftarrow$ & $\leftarrow$ & $\leftarrow$ & $\leftarrow$ & $\leftarrow$ \\
\hline \multirow[t]{2}{*}{ Pre } & quantity & {$\left[\mathrm{mm}^{3} /\right.$ cycle] } & 1.8 & $\leftarrow$ & $\leftarrow$ & $\leftarrow$ & $\leftarrow$ & $\leftarrow$ & $\leftarrow$ & $\leftarrow$ & $\leftarrow$ \\
\hline & timing & [ $\left.{ }^{\circ} \mathrm{ATDC}\right]$ & -9.3 & $\leftarrow$ & $\leftarrow$ & -12.3 & $\leftarrow$ & $\leftarrow$ & $\leftarrow$ & $\leftarrow$ & $\leftarrow$ \\
\hline \multirow{2}{*}{$\begin{array}{c}1^{\mathrm{st}} \\
\text { Main }\end{array}$} & quantity & [mm³/cycle] & 43.5 & 42.9 & 42.4 & 42.2 & 40.8 & 38.4 & 36.0 & 33.4 & 33.1 \\
\hline & timing & [ $\left.{ }^{\circ} \mathrm{ATDC}\right]$ & -1.8 & $\leftarrow$ & $\leftarrow$ & -4.8 & $\leftarrow$ & $\leftarrow$ & $\leftarrow$ & $\leftarrow$ & $\leftarrow$ \\
\hline \multirow{2}{*}{$\begin{array}{c}2^{\text {nd }} \\
\text { Main }\end{array}$} & quantity & {$\left[\mathrm{mm}^{3} /\right.$ cycle] } & - & - & - & - & 1.2 & 2.8 & 5.4 & 7.9 & 6.0 \\
\hline & timing & {$\left[{ }^{\circ} \mathrm{ATDC}\right]$} & - & - & - & - & 10.2 & 11.2 & 10.1 & 8.9 & 8.4 \\
\hline \multirow{2}{*}{$\begin{array}{c}3^{\text {rd }} \\
\text { Main }\end{array}$} & quantity & {$\left[\mathrm{mm}^{3} /\right.$ cycle] } & - & - & - & - & - & - & - & - & 2.4 \\
\hline & timing & {$\left[{ }^{\circ} \mathrm{ATDC}\right]$} & - & - & - & - & - & - & - & - & 18.4 \\
\hline \multicolumn{2}{|c|}{ EGR rate } & [\%] & 10.2 & 13.2 & 14.8 & 18.5 & 20.0 & 19.2 & 19.8 & 18.8 & 19.8 \\
\hline \multicolumn{2}{|c|}{ Intake $\mathrm{O}_{2}$ conc. } & {$[\%]$} & 19.4 & 19.0 & 18.6 & 18.0 & 17.9 & 17.9 & 17.9 & 18.1 & 17.8 \\
\hline
\end{tabular}

an error derived from the device. Therefore, the conversion factor from the sensor output to the injection rate was determined so that the integral value of the section excluding the skirt part of the end of injection coincided with the injection quantity. In the case of splitmain injection, the skirt of the first part of the main injection overlaps the waveform of the second part of the main injection as shown in Figure 6 . Therefore, there is a possibility the injection rate at the second part of main injection is higher than the actual value.

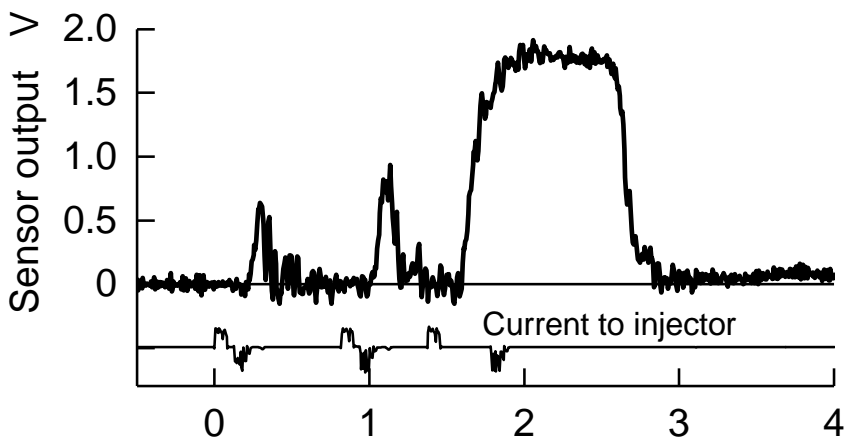

Time from pilot injection signal ms

Figure 5. Sensor output of injection rate meter of p160 (50 cycle average).

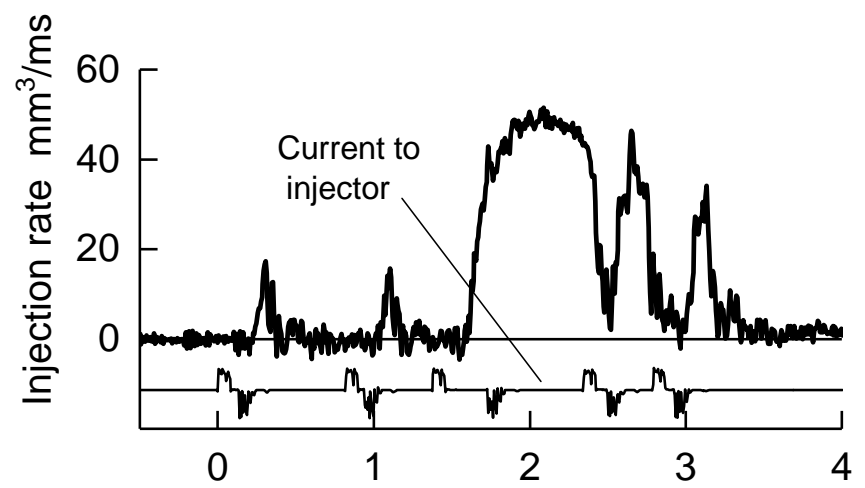

Time from pilot injection signal ms

\section{Numerical Setup}

\section{Degree of constant volume}

The degree of constant volume (DCV) is a value indicating how close the combustion is to the Otto cycle, and it is calculated by the following equation [10]

$$
D C V=\frac{1}{Q} \int \frac{d Q}{d \theta}\left\{\frac{1-1 / \epsilon_{\theta}^{\kappa-1}}{1-1 / \epsilon^{\kappa-1}}\right\} d \theta
$$

where $\mathrm{d} Q / \mathrm{d} \theta$ is the heat release rate, $Q$ is integral of $\mathrm{d} Q / \mathrm{d} \theta, \varepsilon$ is a compression ratio, and $\varepsilon_{\theta}$ is an effective compression ratio at crank angle $\theta$.

\section{Heat-Balance Analysis}

Net indicated work, unburned loss, exhaust loss, and cooling loss were considered to determine heat balance. The net indicated work was calculated based on in-cylinder pressure; the unburned loss was calculated based on exhaust gas analysis results; and the exhaust loss was defined as the difference of enthalpies between intake and exhaust gases. The enthalpy flow rates of intake and exhaust gases were calculated based on the components and measured temperature. The intake and exhaust temperatures were measured using thermocouples with a $3.2 \mathrm{~mm}$ sheath diameter. The thermocouple for the intake temperature was mounted at $400 \mathrm{~mm}$ upstream from the intake valve, where the thermocouple was insulated from the cylinder head. The thermocouple for exhaust temperature was mounted at 150 $\mathrm{mm}$ downstream from the exhaust valve, just after the outlet of the cylinder head. A low fluctuation of the measured temperature was indicated because the sheath diameters were fairly thick. The cooling loss was defined as the residue in the input heat after excluding the indicated work, unburned loss, and exhaust loss.

In addition, to verify the heat balance, the tendency of cooling loss was compared with the trend of cooling loss calculated using the method of List [11]. In the method, the indicated thermal efficiency $\eta_{i}$ is expressed as

$$
\eta_{i} \cong \eta_{t h} \cdot \eta_{c o m b} \cdot\left(1-\eta_{c}\right) \cdot D C V
$$

Page 3 of 12 
where $\eta_{\text {th }}$ is the theoretical thermal efficiency of the Otto cycle, $\eta_{\text {comb }}$ is the combustion efficiency, and $\eta_{\mathrm{c}}$ is the cooling loss ratio for heat release. Since the theoretical efficiency, combustion efficiency, and DCV are known, the cooling loss by List's method $\eta_{\mathrm{c}, \mathrm{L}}$ can be obtained by the following equation:

$$
\eta_{c, L} \equiv 1-\frac{\eta_{i}}{\eta_{t h} \cdot \eta_{c o m b} \cdot D C V}
$$

\section{CFD Simulation}

A CFD simulation was performed using AVL FIRE® v2013.2. The major sub-models used in the simulation are listed in Table 3. The liquid phase of the fuel was treated by a discrete droplet method, and the Kelvin-Helmholtz/Rayleigh-Taylor (KH-RT) model was adopted for spray breakup. The model constants for the KH-RT model were used according to the FIRE ${ }^{\circledR}$ recommendation $\left(\mathrm{C}_{1}=\right.$ $0.61, C_{2}=12$ ) [12]. The initial spray angle was set at $12^{\circ}$ as a standard. The fuel properties of 1-D Diesel [13] were applied. The Dukowicz model [12] was applied as the evaporation model, and the ECFM-3Z model [14] was used as the combustion model. The standard wall function was used as a wall heat transfer model.

Table 3. Software and sub models used in CFD.

\begin{tabular}{|l|c|}
\hline CFD solver & AVL FIRE® v2013.2 \\
\hline Turbulence & k-zeta-f \\
\hline Spray breakup & KH-RT \\
\hline Evaporating & Dukowicz \\
\hline Combustion & ECFM-3Z \\
\hline
\end{tabular}

Since the purpose of the CFD calculation is to understand the effects of injection pressure and the pattern, the injection rate shape was simplified. That is, the total injection quantity was fixed at $44 \mathrm{~mm}^{3}$, and the injection rate of the first part of the main injection was provided as a trapezoid and the other parts were given as triangles.

\section{Result and Discussion}

\section{Effect of Injection Pressure}

First, the experiments were conducted to investigate the effects of high injection pressure on thermal efficiency. The injection pressure was set at $160 \mathrm{MPa}, 200 \mathrm{MPa}$, and $270 \mathrm{MPa}$ (Case p160, p200, and p270). In addition, the injection timing was advanced $3^{\circ} \mathrm{CA}$ from the case p270 (p270A). The in-cylinder pressure, heat release rate, and injection rate are illustrated in Figure 7. For all experiments, the ignition delay of the main-injection spray was extremely short. The heat release rate increased with the increase in injection pressure, and hence, the maximum in-cylinder pressure increased. Since the ignition timing was advanced for the earlier injection timing, the maximum in-cylinder pressure increased.

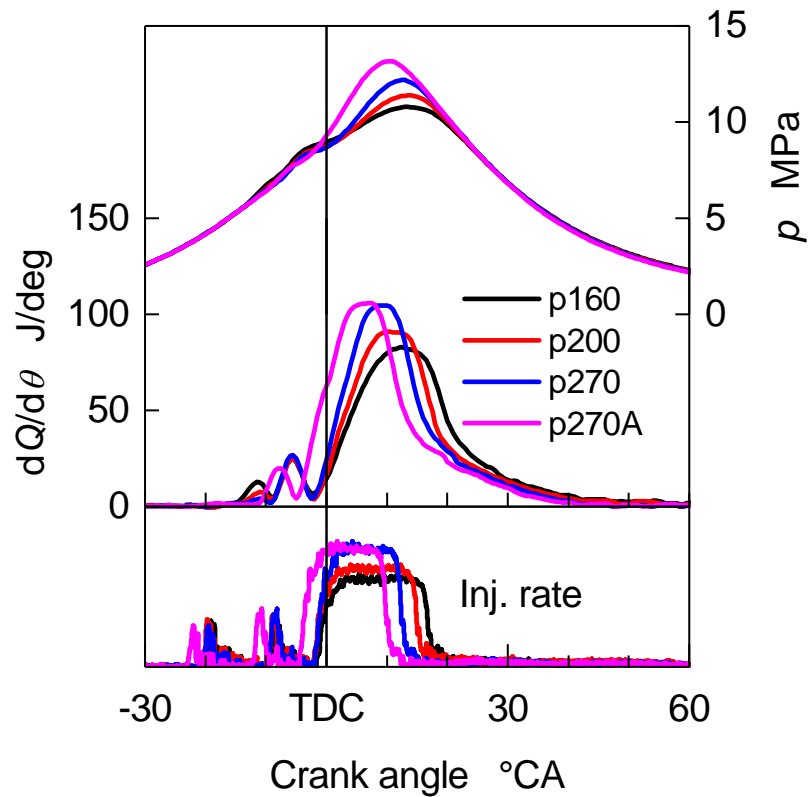

Figure 7. Effects of injection pressure and injection timing on in-cylinder pressure, heat-release rate, and injection rate (p160, p200, p270, and p270A).

Before referring to heat balance, two methods were employed to verify the trend of the cooling loss ratio. Figure 8 shows the cooling loss ratios as residue and List's method. Although the absolute value is different, the trends of cooling loss obtained by two methods are the same.

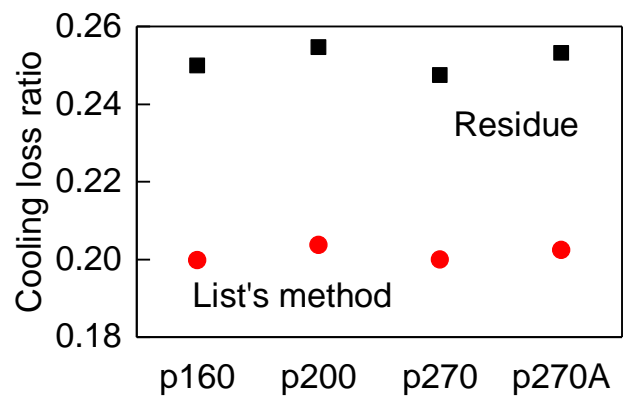

Figure 8. Comparison of cooling loss ratios by two calculation methods.

Figure 9 shows the DCV and heat balance. The heat balance was determined based on the exhaust loss due to temperature measurement and the cooling loss due to the residue. As the figure indicates, both the increase in injection pressure and the advance of injection timing can lead to the higher indicated thermal efficiency (shown as indicated work in the figure). The increase of DCV is predominant for higher thermal efficiency, and exhaust loss is decreased. The effect of injection pressure or advanced injection on the cooling loss is not clear. As listed in Table 2, the intake oxygen concentration is lowered with an increase in injection pressure or advanced injection timing. The trend of thermal efficiency depends on the balance of opposite effects of injection pressure and oxygen concentration. 

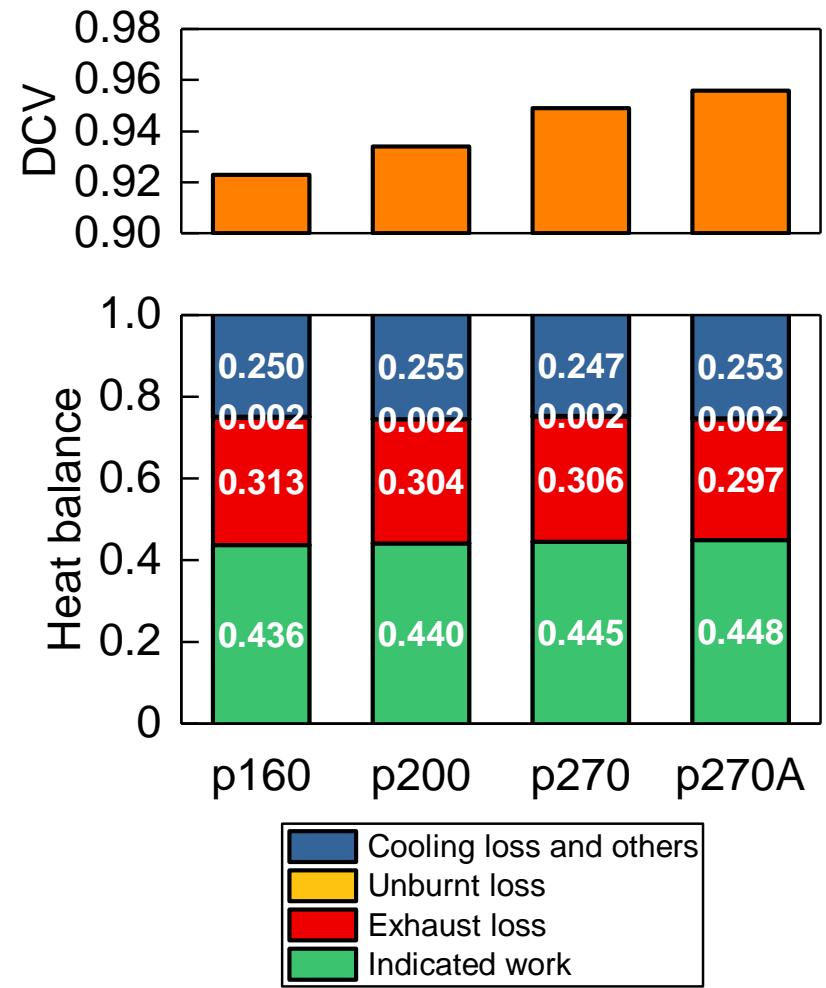

Figure 9. Effects of injection pressure and injection timing on degree of constant volume (DCV) and heat balance (p160, p200, p270, and p270A).

The exhaust emissions shown in Figure 10 indicate that the smoke, $\mathrm{CO}$, and THC emissions are significantly low for all experiments. CO and smoke emissions decreased when increasing injection pressure.

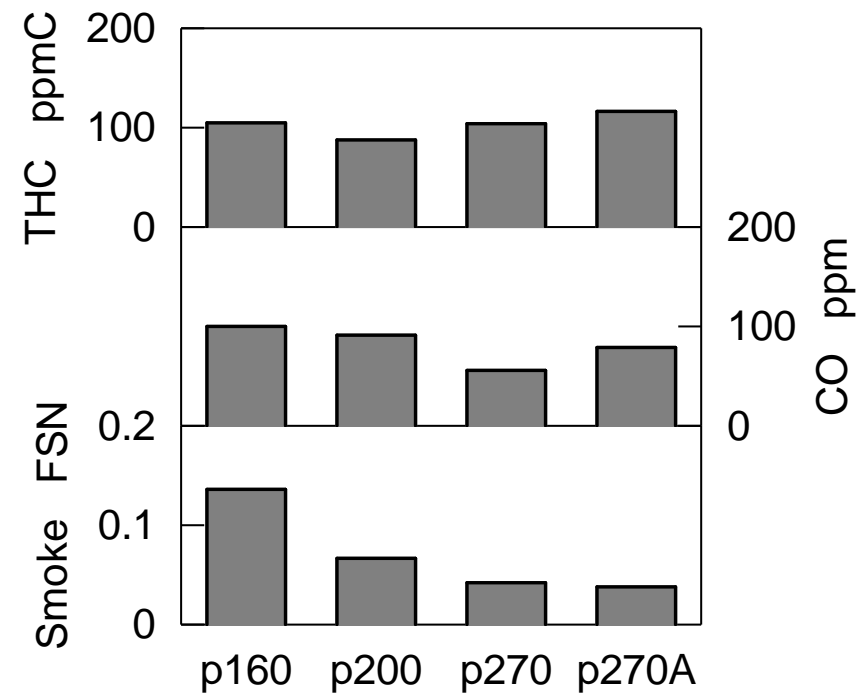

Figure 10. Effect of injection pressure and injection timing on THC, CO, and Smoke emission (p160, p200, p270, and p270A).

\section{Effect of Split-Main Injection}

In order to further improve the thermal efficiency, the main injection was split into two stages with an injection pressure of $270 \mathrm{MPa}$. The injection quantity ratio was set as shown in Table 2 (from A1 through A8). In addition, the main injection was divided into three stages in

Page 5 of 12 the case DA. In these cases, the injection interval was minimized in order to suppress the increase in injection duration. Figure 11 shows the injection rates, heat release rates $\mathrm{d} Q / \mathrm{d} \theta$, accumulated heat release ratio $X$, and in-cylinder pressures $p$ for the injection patterns $\mathrm{p} 270 \mathrm{~A}$, $\mathrm{A} 3, \mathrm{~A} 8$, and DA. The results show that the peak of the heat release rate decreased by splitting the main injection. The heat release rates from $5^{\circ} \mathrm{ATDC}$ to $10^{\circ} \mathrm{ATDC}$ were lowered by splitting the main injection. However, the heat release rates close to $15^{\circ} \mathrm{ATDC}$ were higher due the combustion of the second part of the main injection. Thus, the accumulated heat release ratios of the split-main injection caught up with that of the single main injection by $30^{\circ}$ ATDC. As a result, the total combustion durations with the split-main injection become shorter than or equal to that of single-stage main injection.

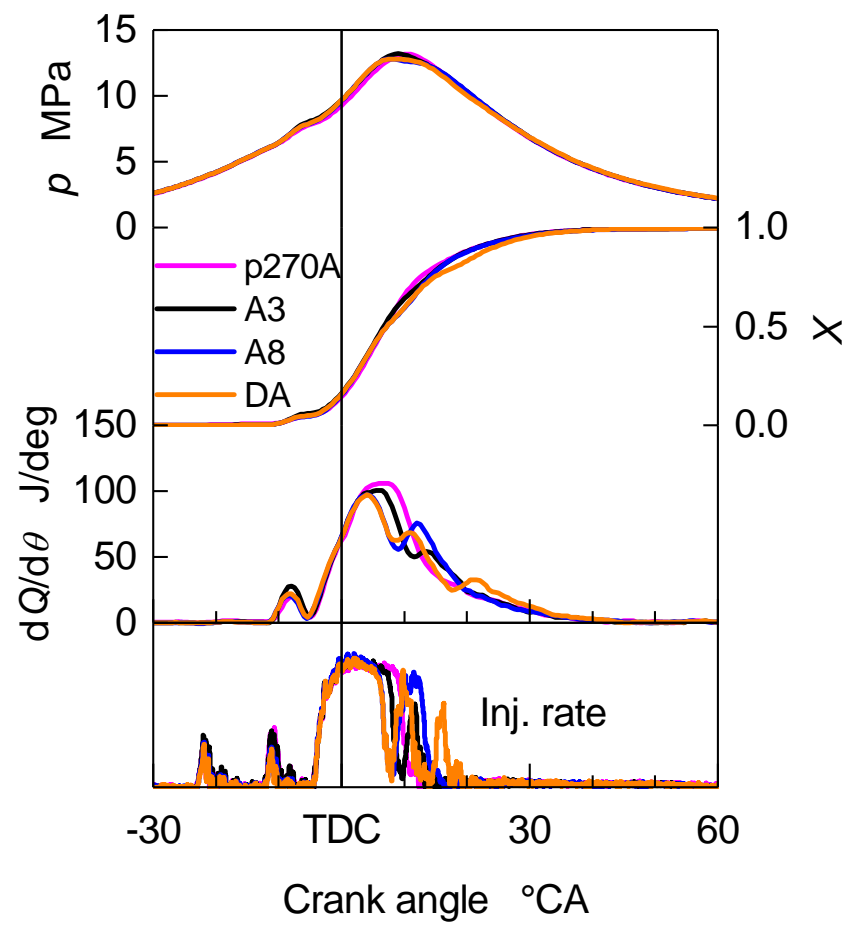

Figure 11. Effect of split injection on in-cylinder pressure $p$, accumulated heat release ratio $X$, heat-release rate $\mathrm{d} Q / \mathrm{d} \theta$, and injection rate (p270A, $\mathrm{A} 3, \mathrm{~A} 8$, and DA)

Figure 12 shows the cooling loss ratios as residue and List's method. In both methods, the cooling loss ratio tends to decrease as the increase in the mass of the second part of the main injection, and the case DA tends to decrease further.

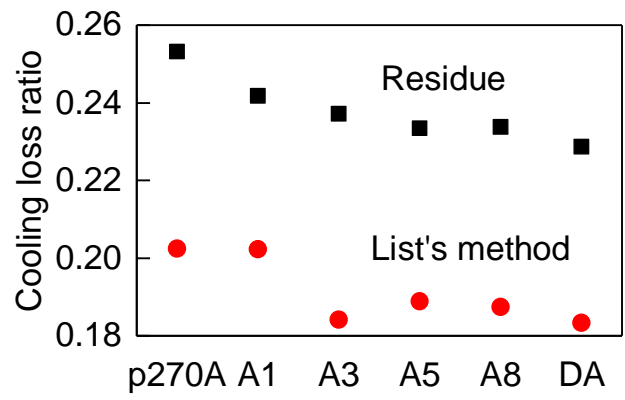

Figure 12. Comparison of cooling loss ratios by two calculation methods in the cases of split main injection. 
Table 4. Injection conditions in CFD simulation.

\begin{tabular}{|c|c|c|c|c|c|c|c|c|c|c|c|}
\hline \multicolumn{3}{|c|}{ Case } & C-p160 & C-p200 & C-p270 & C-p270A & $\mathrm{C}-\mathrm{A} 2$ & C-A4 & C-A6 & C-A8 & C-DA \\
\hline \multicolumn{2}{|c|}{ Inj. pressure } & [MPa] & 160 & 200 & 270 & $\leftarrow$ & $\leftarrow$ & $\leftarrow$ & $\leftarrow$ & $\leftarrow$ & $\leftarrow$ \\
\hline \multirow[t]{2}{*}{ Pilot } & quantity & {$\left[\mathrm{mm}^{3} /\right.$ cycle $]$} & 1.7 & $\leftarrow$ & $\leftarrow$ & $\leftarrow$ & $\leftarrow$ & $\leftarrow$ & $\leftarrow$ & $\leftarrow$ & $\leftarrow$ \\
\hline & timing & [ $\left.{ }^{\circ} \mathrm{ATDC}\right]$ & -20.3 & $\leftarrow$ & $\leftarrow$ & -23.3 & $\leftarrow$ & $\leftarrow$ & $\leftarrow$ & $\leftarrow$ & $\leftarrow$ \\
\hline \multirow[t]{2}{*}{ Pre } & quantity & {$\left[\mathrm{mm}^{3} /\right.$ cycle] } & 1.8 & $\leftarrow$ & $\leftarrow$ & $\leftarrow$ & $\leftarrow$ & $\leftarrow$ & $\leftarrow$ & $\leftarrow$ & $\leftarrow$ \\
\hline & timing & {$\left[{ }^{\circ} \mathrm{ATDC}\right]$} & -9.3 & $\leftarrow$ & $\leftarrow$ & -12.3 & $\leftarrow$ & $\leftarrow$ & $\leftarrow$ & $\leftarrow$ & $\leftarrow$ \\
\hline \multirow{2}{*}{$\begin{array}{c}1^{\text {st }} \\
\text { Main }\end{array}$} & quantity & [mm³/cycle] & 40.5 & 40.5 & 40.5 & 40.5 & 38.5 & 36.5 & 34.5 & 32.5 & 32.5 \\
\hline & timing & {$\left[{ }^{\circ} \mathrm{ATDC}\right]$} & -1.8 & $\leftarrow$ & $\leftarrow$ & -4.8 & $\leftarrow$ & $\leftarrow$ & $\leftarrow$ & $\leftarrow$ & $\leftarrow$ \\
\hline \multirow{2}{*}{$\begin{array}{c}2^{\text {nd }} \\
\text { Main }\end{array}$} & quantity & {$\left[\mathrm{mm}^{3} /\right.$ cycle $]$} & - & - & - & - & 2 & 4 & 6 & 8 & 6 \\
\hline & timing & {$\left[{ }^{\circ} \mathrm{ATDC}\right]$} & - & - & - & - & 9.5 & 8.9 & 8.3 & 7.7 & 7.7 \\
\hline \multirow{2}{*}{$\begin{array}{c}3^{\text {rd }} \\
\text { Main }\end{array}$} & quantity & {$\left[\mathrm{mm}^{3} /\right.$ cycle $]$} & - & - & - & - & - & - & - & - & 2 \\
\hline & timing & {$\left[{ }^{\circ} \mathrm{ATDC}\right]$} & - & - & - & - & - & - & - & - & 12.1 \\
\hline \multicolumn{2}{|c|}{ Intake $\mathrm{O}_{2}$ conc. } & [\%] & 19.4 & 19.2 & 18.6 & 18.3 & 18.3 & 18.3 & 18.3 & 18.3 & 18.3 \\
\hline
\end{tabular}

The heat balance results of the cases p270A, A1 through A8 and DA are shown in Figure 13. They were calculated in the same manner as in Figure 9. When the injection mass of the second part of the main injection was set to $1.2 \mathrm{~mm}^{3} /$ cycle (A1), the DCV increased slightly compared to the injection pattern without split-main injection (p270A). As the injection mass ratio of the second part of the main injection increases, the DCV decreases gradually due to the longer injection duration while the cooling loss ratio is reduced. As a result, the indicated thermal efficiency is increased for the split-main injection cases (A1 through A8) compared with the single-stage main injection case (p270A). It is also the case with the three-stage main injection (DA), although the injection duration is longer than the case of single- or two-stage main injection. Thus, higher thermal efficiency can be obtained using split-main injection if the increase in the injection duration is mitigated by reduction of the dwell between the injection stages.
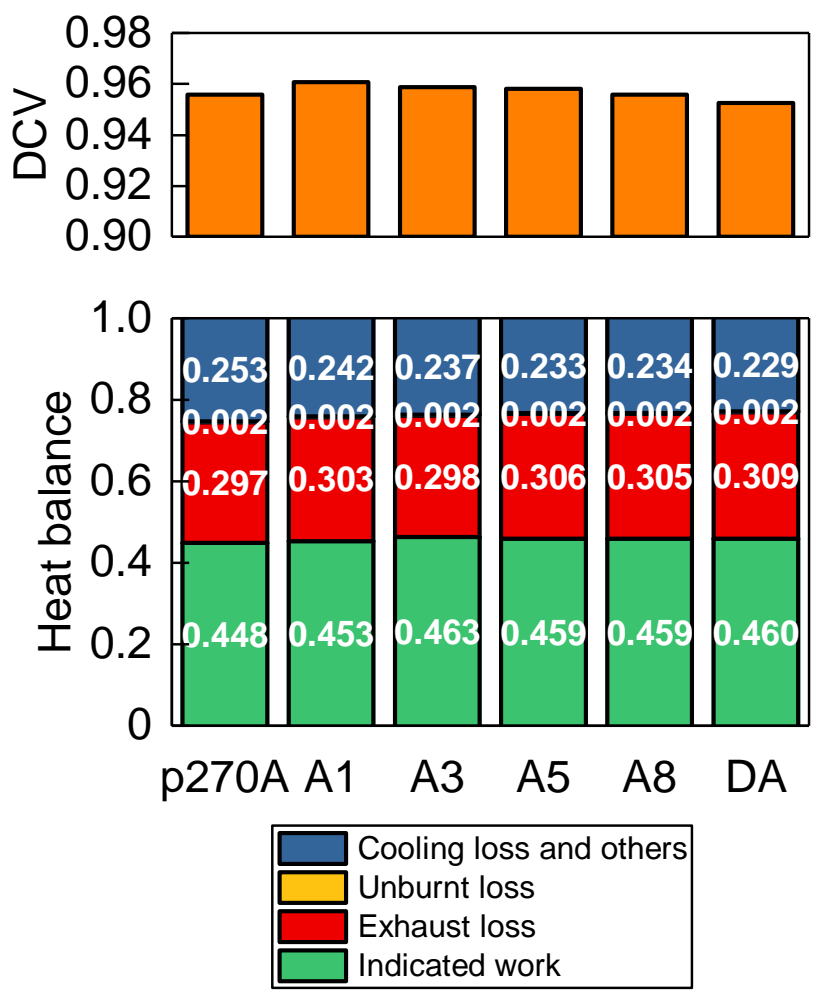

Figure 13. Effect of split injection on DCV and heat balance.

Page 6 of 12
The exhaust emissions are shown in Figure 14. Although the smoke of A8 is slightly high, significant deterioration is not observed by split injection.

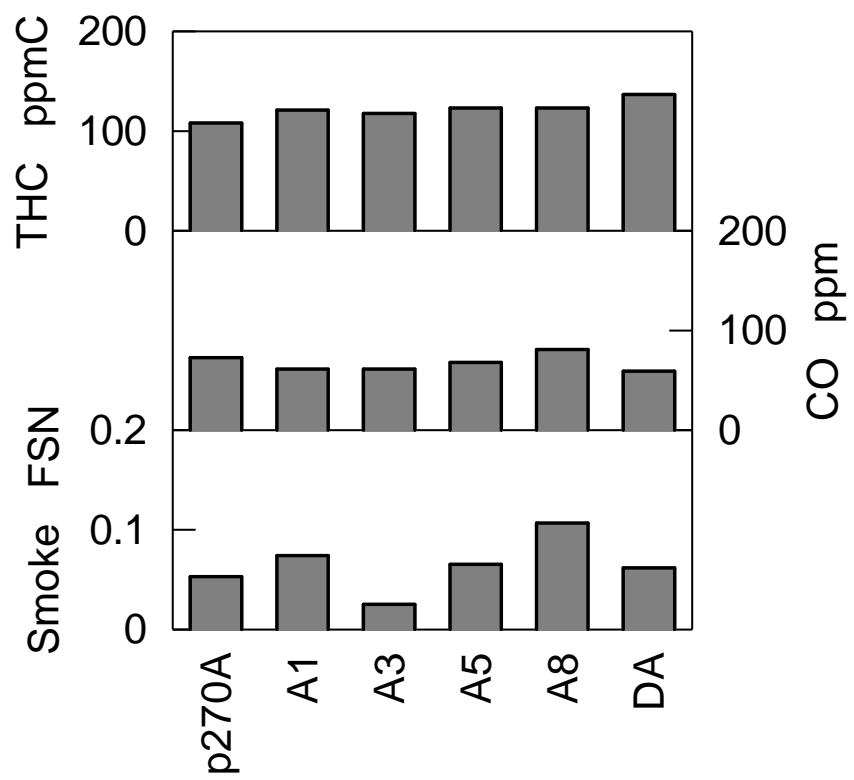

Figure 14. Effect of splitting main injection on THC, CO, and smoke emission.

\section{CFD Analysis}

CFD analysis was conducted to investigate the development of fuel spray and flame in order to clarify the impact of split-main injection on thermal efficiency and cooling loss. For the simulations, the total injection quantity was fixed at $44 \mathrm{~mm}^{3}$ and the quantities of the second part of the main injection were varied from $2-8 \mathrm{~mm}^{3}$. The mass rate of the first part of the main injection was assumed to be a trapezoid and other parts were triangles. The dwell between the parts in main injection was set to zero. The detailed calculation conditions are listed in Table 4.

In order to demonstrate the validity of the simulation, the experimental and simulated injection rate, in-cylinder pressure, and heat release rate are illustrated in Figure 15. The heat release rates of CFD results were calculated in the same manner as the experimental results. In addition, the indicated work $W_{\mathrm{i}, 120}$, cooling loss $Q_{\mathrm{c}, 120}$, and DCV are shown in Figure 16 . The $W_{\mathrm{i}, 120}$ and $Q_{\mathrm{c}, 120}$ are the integrated work and cooling loss from $-120^{\circ}$ ATDC to $120^{\circ}$ ATDC. 

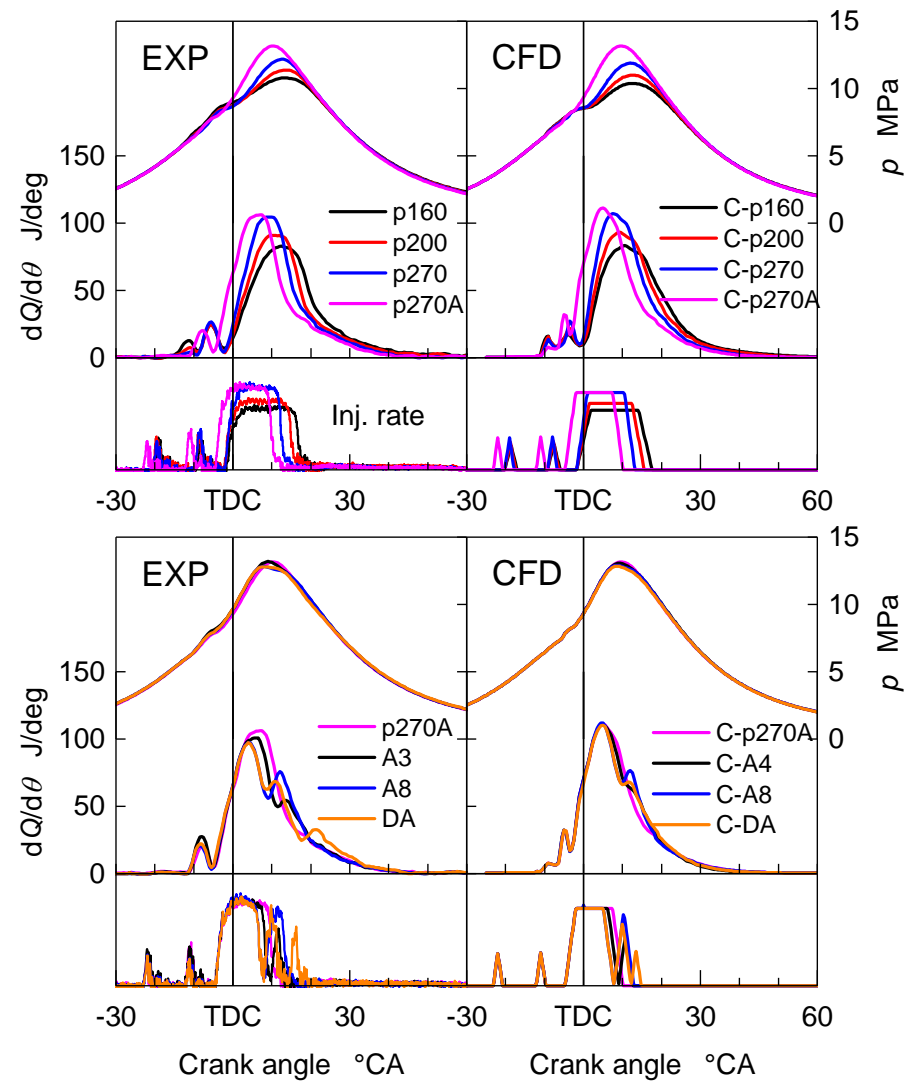

Figure 15. Comparison of in-cylinder pressure, heat release rate, and injection rate between experiments and simulations.
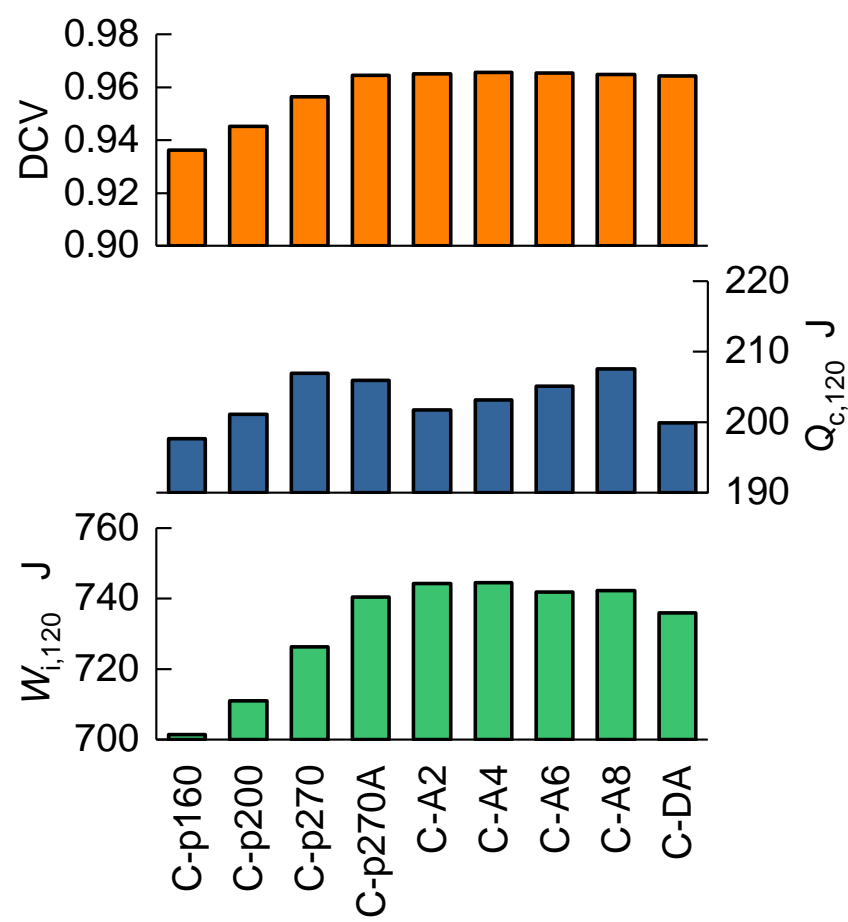

Figure 16. Degree of constant volume, cooling loss, and indicated work in CFD simulation.

Page 7 of 12
As shown in Figure 15, the increase in the injection pressure increases the peak of the heat release rate $\mathrm{d} Q / \mathrm{d} \theta$ and shortens the combustion duration, which is the same trend as the experimental result. In the case of adopting the split-main injection, the decay of the heat release rate by the first part of main injection is accelerated and the heat release rate by the second part of the main injection becomes noticeable by increasing the amount of the second part of the main injection. Although the heat release rates by the second part of the main injection in CFD tend to be smaller than those of the experiments, the overall features of heat release rates of CFD are in good agreement with the experimental results.

Further, the comparison of Figure 9, 13, and 16 indicates that the DCV trend corresponds well with the experimental results. On the other hand, unlike the experimental results, cooling loss increases with an increase in injection pressure and fuel mass ratio in the second part of the main injection. The fuel quantity of the experiment decreased according to increasing injection pressure, while that of CFD was set constant. It seems that the effect of the change of the fuel quantity is remarkable. Although the fuel quantity of the experiment was almost constant, the cooling loss with the split main injection in CFD obviously contradicts the experimental result.

Figure 17 shows the rate of cooling loss rate through the walls $\mathrm{d} Q_{\mathrm{c}} / \mathrm{d} t$ and the accumulated cooling loss $Q_{c}$, and Figure 18 illustrates the wall heat flux and the isosurface of the equivalence ratio $(E R)=1$. As shown in the graph, for the split-main injection cases (C-A2 through C-A8), the maximum cooling loss rate around $10^{\circ} \mathrm{ATDC}$ is lower and the cooling loss rate after $15^{\circ} \mathrm{ATDC}$ is higher compared with the case without split (C-p270A). As shown in Figure 18, the high heat flux is observed at an area where the spray flame impinges at $10^{\circ}$ ATDC shortly after the end of the first part of the main injection. With a decrease in the injection mass of the first part of the main injection, the high heat flux region becomes smaller. The lower maximum cooling loss rate is caused by the reduced amount of the first part of the main injection, which weakens the spray flame impingement on the wall. The second part of the main injection causes a higher cooling loss rate because the spray flames reach the wall around $15^{\circ} \mathrm{ATDC}$. At $15^{\circ} \mathrm{ATDC}$ through $30^{\circ} \mathrm{ATDC}$, a higher heat flux is found for cases with a larger second part of the main injection. Thus, the total cooling loss depends on the balance between the cooling loss by the first and second main spray. The experimental results indicate that the effect of the reduced first part of the main injection is fully utilized by mitigating the additional cooling loss from the second part of the main spray. However, the calculations do not capture the trends in the experiments. 


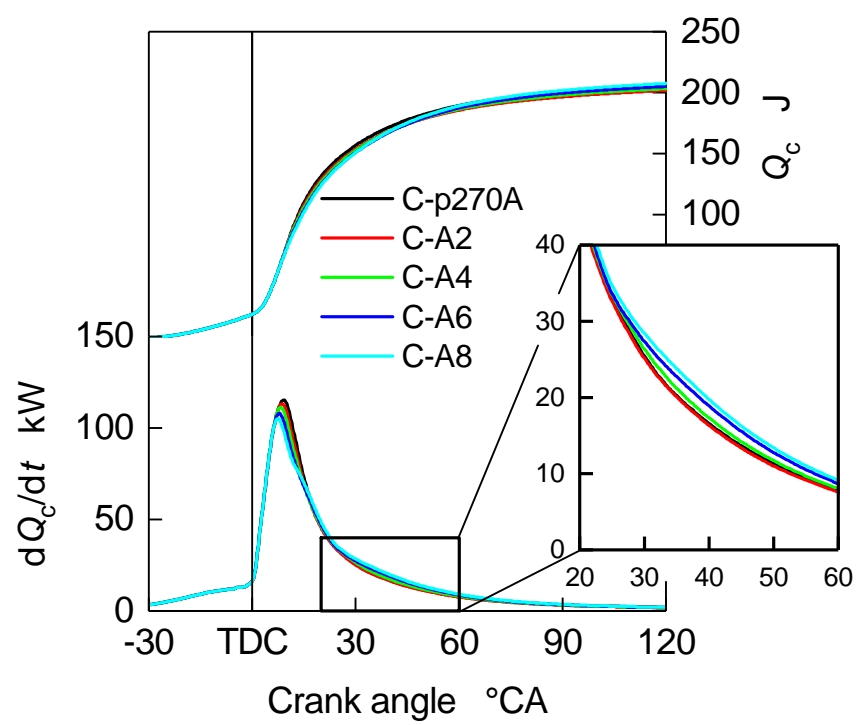

Figure 17. Cooling loss $Q_{c}$ and cooling loss rate $\mathrm{d} Q_{d} / \mathrm{d} t$ in CFD simulation.

The opposite dependence of cooling loss on the split ratio between experimental and simulated results can be attributed to the overestimation of the cooling loss rate by the second part of the main spray. To solve this problem, improvement is required for prediction of sprays and flames development especially in the case of smallquantity injection, which corresponds to the second part of the main injection.

The injection quantities of the second and third part of the main injection are much smaller than that of the first part of the main injection. The fuel injection rate increases and then decreases without a steady portion, as shown in Figure 15. In such an injection process, the influence of the transient needle motion on the nozzle-exit flow is significant. Several studies show that the nozzle-exit flow spreads at the start and end of injection when the needle lift is quite low [15-17]. This is because the flow inside the nozzle hole has a radial component that comes from the vortex in the sac [16, 17]. To simulate this effect in a simple manner, a wider initial spray angle was selected for the second part of the main injection. The angle was set at $24^{\circ}$, which was double the standard angle.

Figure 19 illustrates the wall heat flux and isosurface of equivalence ratio $(E R)=1$ with a second-main-spray cone angle of $24^{\circ}$, and Figure 20 compares the heat release rates of the standard and wider cone angles for the cases C-A4 and C-A8. The comparison of Figure 18 and Figure 19 indicates that the wider spray cone angle leads to wider and weaker spray jets by the second part of main injection. In both the cases, the maximum heat flux at $15^{\circ} \mathrm{ATDC}$ is clearly lowered. However, the difference in the heat release rates is small as shown in Figure 20. 


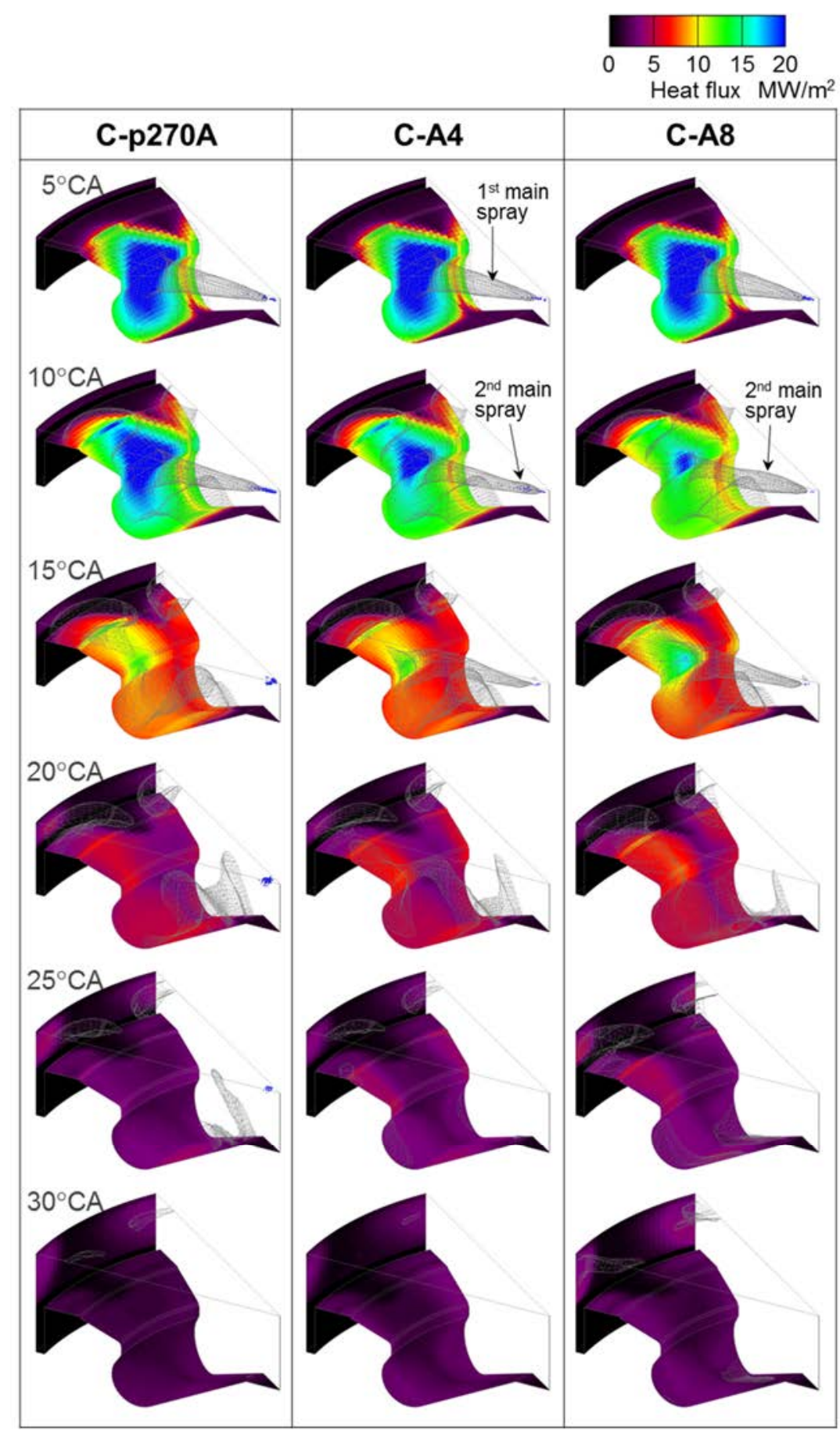

Figure 18. Heat flux and isosurface of $\mathrm{ER}=1$.

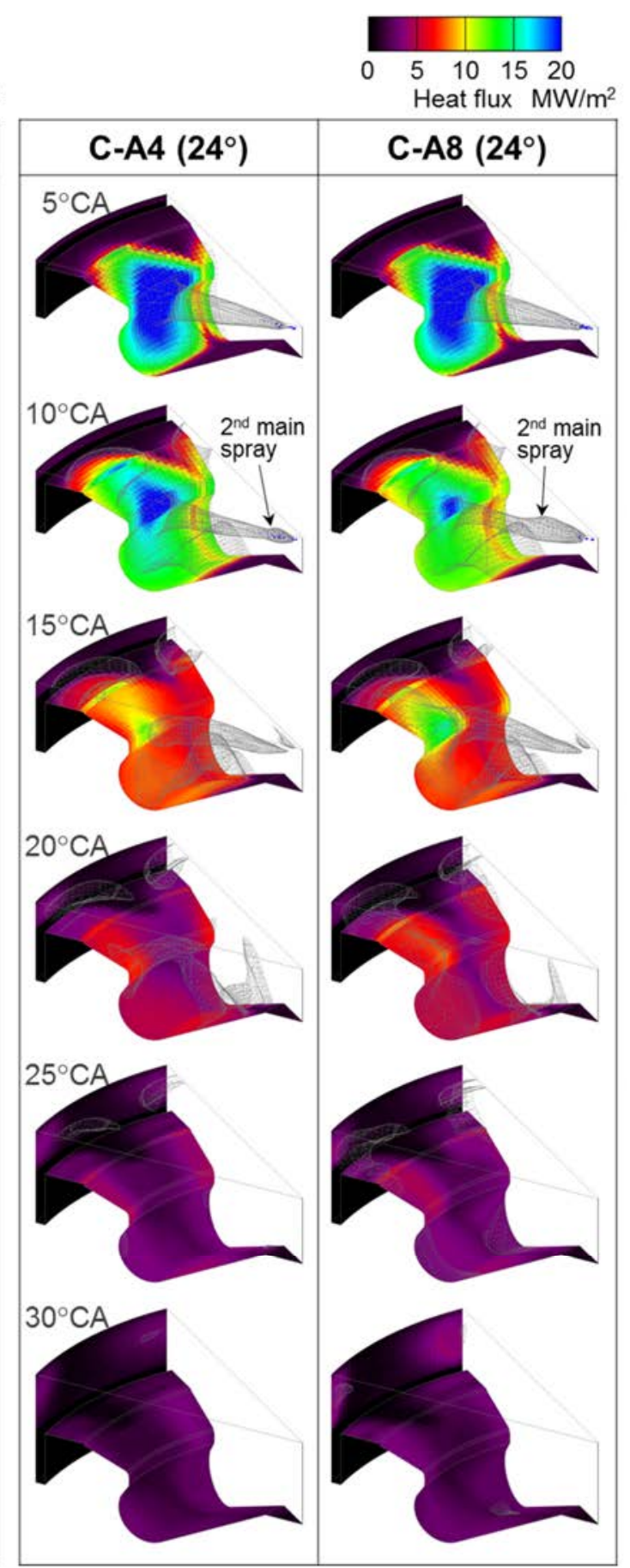

Figure 19. Heat flux and isosurface of ER $=1$ (The cone angle of second part of split main injection: $24^{\circ}$ ). 

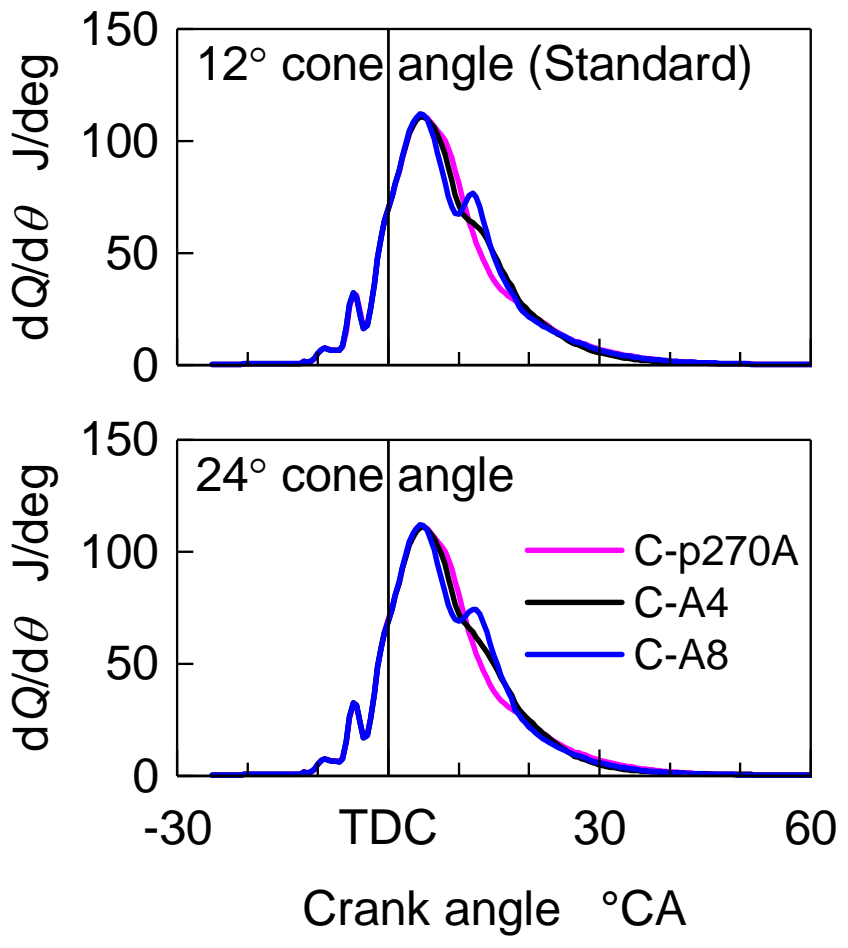

Figure 20 . Heat release rate with $24^{\circ}$ cone angle of second-part main injection in CFD simulation.

The $W_{\mathrm{i}, 120}, Q_{\mathrm{c}, 120}$, and DCV are illustrated in Figure 21. The DCV trend is not influenced by the change in the spray cone angle and the change is smaller than the experimental results. The same thermal efficiency trend was reproduced with the conditions of the small second-main injection. The cooling loss decreases as the amount of the second part of the main injection increases for the cases C-A2 and C-A4, which coincides with the experimental results. However, the cooling loss increases along with an increase in the second-part fuel mass ratio for the cases C-A6 and C-A8.

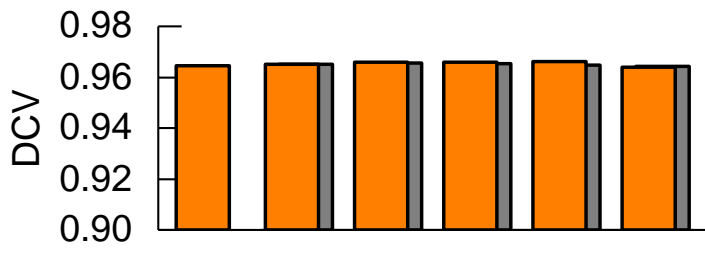

Cone angle: $24^{\circ}$ Standard cone angle
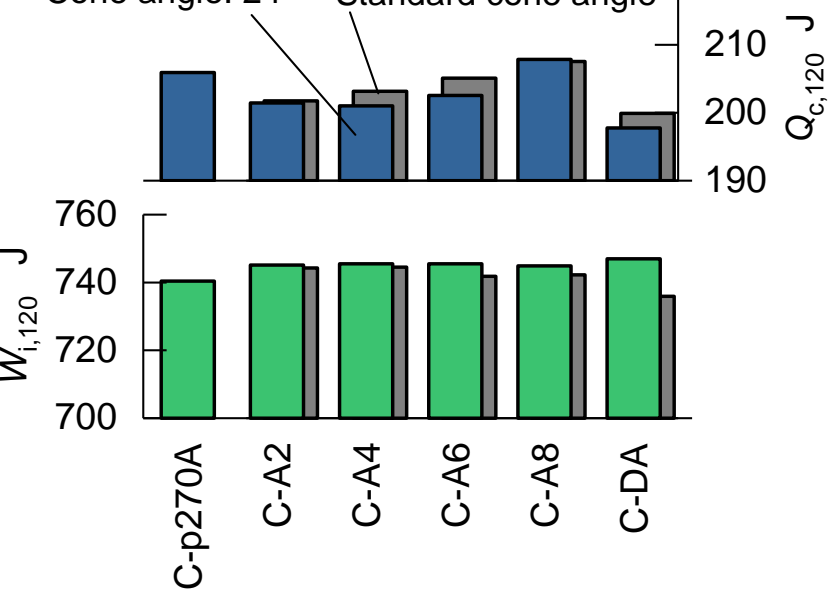

Figure 21. The effect of spray cone angle of second part of main injection on $\mathrm{DCV}$, cooling loss $Q_{\mathrm{c}, 120}$, and indicated work $W_{\mathrm{i}, 120}$.

In order to reveal the reasons behind the increasing cooling loss along with the increase in the fuel mass ratio of the second part under wider spray cone angle conditions, local cooling losses are compared for the cases C-A4 and C-A8. Figure 22 shows the accumulated cooling loss through the surfaces of piston, cylinder head, and cylinder liner. As mentioned before, increasing the initial spray cone angle provides a reduced wall heat flux through the piston. Thus, the influence of the spray cone angle on the accumulated cooling loss through the piston is equivalent for both the cases. The difference in the influence of spray angle is found in the cooling loss through the cylinder liner, which is caused by the flame flowing out of the piston bowl. The cooling loss is reduced in the case C-A4, while it hardly changes for $\mathrm{C}$-A8. This indicates that the mitigation of the spray-wall impingement leads to the reduced amount of the flame only for the case of smaller injection quantity.

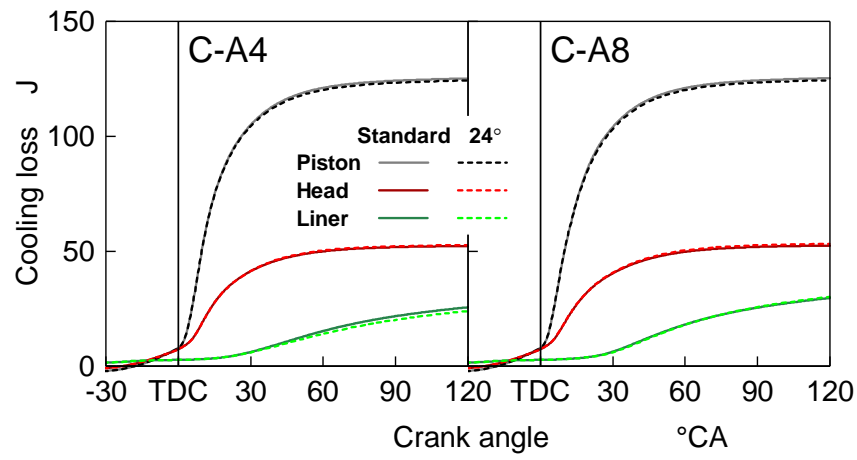

Figure 22. Effects of spray cone angle on cooling loss.

Based on the above discussion, modeling to describe the development of a spray and flame for a relatively small amount of injection is important for the accurate prediction of cooling loss. In particular, it 
is necessary to enhance a database and construct models for the dynamic change of the spray angle.

\section{Summary}

Aiming at the improvement of the trade-off relation between DCV and cooling loss, an experimental study was carried out using a single-cylinder diesel engine with an $85 \mathrm{~mm}$ bore. The effects of injection pressure and split-main injection with near-zero dwell were investigated. In addition, the factors affecting the thermal efficiency was discussed based on the results of heat-balance analysis and CFD simulation.

Thermal efficiency is improved by the combination of an increase in injection pressure up to $270 \mathrm{MPa}$, advanced injection timing, and split-main injection with a near-zero dwell because the increase in combustion duration is suppressed and the advantage of split injection can be fully utilized. As the injection mass ratio of the second part of the main injection increases, the cooling loss through the wall become smaller. The cooling loss depends on the balance of cooling loss due to the first and second parts of the main injection. However, in the CFD simulation, the cooling loss trend according to the splitting ratio of the main injection is contradictory to the experimental results if the same spray cone angle is applied to the first and second part of the main injection. The trend is improved by a simple manner of adopting the wider spray cone angle to the second part of main injection.

For a more accurate prediction of cooling loss, further studies are needed to improve the initial droplet size, spray cone angle, and wall heat transfer, especially for small-amount injection.

\section{References}

1. Singh, S., "Super Truck Program: Engine Project Review Recovery Act - Class 8 Truck Freight Efficiency Improvement Project,"

https://www.energy.gov/sites/prod/files/2015/06/f23/ace058_sin gh_2015_o.pdf, (accessed March 12, 2018)

2. National Science Foundation Directorate for Engineering. NSF/DOE partnership on advanced combustion engines. NSF Solicitation 12-559; 2012.

3. "Clean High-Efficiency Diesel Engine VII (CHEDE-VII)," https://www.swri.org/consortia/clean-high-efficiency-dieselengine-vii-chede-vii (accessed May 25, 2018)

4. "Cross-ministerial Strategic Innovation Promotion Program (SIP)?” http://www8.cao.go.jp/cstp/panhu/sip english/8-11.pdf (accessed December 25, 2017).

5. Osada, H., Aoyagi, Y. and Shimada, K., "Diesel Combustion Improvement Using High Boost, Wide Range and High Rate EGR in a Single Cylinder Engine (Third Report) - Effect of Multi-Injection on Exhaust Emissions and BSFC,” Trans. of JSAE 43(4):855-861, 2012, doi: https://doi.org/10.11351/jsaeronbun.43.855.

6. Horibe, N., Tamura, I., Hamada, T., Liu, L. and Ishiyama, T., "Smoke-Reduction Effect of After Injection in Combination with Pilot Injection,” Trans. of JSAE 43(5):1039-1044, 2012, doi: https://doi.org/10.11351/jsaeronbun.43.1039 (in Japanese).

7. JIS K2249-01, 2011 (in Japanese).

8. JIS K2279, 2003 (in Japanese).

9. Bosch, W., "The Fuel Rate Indicator: A New Measuring Instrument For Display of the Characteristics of Individual
Injection," SAE Technical Paper 660749, 1966, https://doi.org/10.4271/660749.

10. Nagao, F., Internal Combustion Engine Lecture (Upper Volume), 1967 (in Japanese).

11. List, H. Thermodynamik der Verbrennungskraftmaschinen, 1939 (in German).

12. AVL FIRE VERSION 2013.2 Spray Module, 2013.

13. Schetz, J.A. and Fuhs, A.E., "Handbook of Fluid Dynamics and Fluid Machinery," 1996.

14. AVL FIRE VERSION 2013.2 Combustion Module, 2013.

15. Bao, Z., Horibe, N. and Ishiyama, T., "A Study on Diesel Spray Characteristics for Small-quantity Injection,” SAE Technical Paper 2018-01-0283, 2018.

16. Hayashi, T., Basaki, M., Suzuki, M. and Ikemoto, M., "Visualization of Internal Flow and Spray Combustion with Real Size Diesel Nozzle,” Trans. of JSAE 43(6):1251-1256, 2012, doi: https://doi.org/10.11351/jsaeronbun.43.1251 (in Japanese).

17. Moon, S., Gao, Y., Park, S., Wang, J., Kurimoto, N. and Nishijima, Y., "Effect of the number and position of nozzle holes on in- and near-nozzle dynamic characteristics of diesel injection," Fuel 150(15):112-122, 2015, doi: https://doi.org/10.1016/i.fuel.2015.01.097.

\section{Contact Information}

Naoto Horibe: horibe@energy.kyoto-u.ac.jp

\section{Acknowledgments}

The authors would like to thank Masayoshi Furukawa and Ryo Kishigami for their valuable assistance with the experiment. This work was supported by the Council for Science, Technology and Innovation (CSTI), Cross-ministerial Strategic Innovation Promotion Program (SIP), "Innovative combustion technology” (funding agency: JST).

\section{Definitions/Abbreviations}

$\begin{array}{ll}\text { CFD } & \text { Computational fluid dynamics } \\ \mathbf{C O} & \text { Carbon monoxide } \\ \mathbf{C C V} & \text { Carbon dioxide } \\ \mathbf{E R} & \text { Degree of constant volume } \\ \mathbf{I M E P} & \text { Equivalence ratio } \\ \mathbf{N O x} & \text { Indicated thermal efficiency } \\ \mathbf{O} 2 & \text { Nitrogen oxides } \\ \boldsymbol{p} & \text { Oxygen } \\ \mathbf{d Q} / \mathbf{d} \boldsymbol{\theta} & \text { In-cylinder pressure }\end{array}$

$Q_{\mathbf{c}}$ Accumulated cooling loss 
$\mathbf{Q}_{\mathbf{c}, 120} \quad$ Accumulated cooling loss from $-120^{\circ}$ ATDC to $120^{\circ}$ ATDC

$\mathrm{d} Q_{\mathrm{c}} / \mathrm{d} t$

Cooling loss rate

TDC

THC

$W_{\mathrm{i}, 120} \quad$ Integrated indicated work from

$\boldsymbol{X}$ $-120^{\circ}$ ATDC to $120^{\circ}$ ATDC

Top dead center

Total hydrocarbon

Accumulated heat release ratio

Page 12 of 12

$10 / 19 / 2016$ 